OPEN ACCESS

Edited by:

Victoria Showunmi University College London,

United Kingdom

Reviewed by:

Kerry Robinson,

University of North Carolina

Wilmington, United States

Elizabeth C. Reilly,

Loyola Marymount University,

United States

${ }^{*}$ Correspondence:

Shirley Randell

mail@shirleyrandell.com.au

Specialty section:

This article was submitted to

Leadership in Education,

a section of the journal

Frontiers in Education

Received: 09 January 2020

Accepted: 29 July 2020

Published: 19 August 2020

Citation:

Randell S and Yerbury H (2020)

An Exploration of the Metaphors and Images Used to Describe Leadership in Two Different Cultural

Contexts. Front. Educ. 5:151

doi: 10.3389/feduc.2020.00151

\section{An Exploration of the Metaphors and Images Used to Describe Leadership in Two Different Cultural Contexts}

\author{
Shirley Randell ${ }^{* *}$ and Hilary Yerbury ${ }^{2}$ \\ ${ }^{1}$ Conjoint Professor of Practice, School of Education, Faculty of Education and Arts, The University of Newcastle, Callaghan, \\ NSW, Australia, ${ }^{2}$ Independent Scholars Association of Australia, Sydney, NSW, Australia
}

This paper is developed from qualitative data exploring the metaphors used to describe women's leadership in differing cultural contexts. Metaphors are a useful communication tool, allowing us to understand an idea or concept through some other phenomenon. Understandably, studies of metaphor tend to focus on metaphors deriving from the English language and from Western cultures. Our everyday language literature abounds with metaphors that evoke images of the masculine - including of machines, war and fighting, competition, games and sport. Leadership is generally thought of as "a good thing," as something important, carried out by people with desirable attributes, such as courage and insight, or with attractive personalities and good communication skills. Metaphors used in discussing women's leadership in many countries may support this approach, but they do so by highlighting the obstacles women face, for example, the glass ceiling, glass cliff, sticky floors, and the labyrinth. This study attempts to break the mold, investigating the understanding of women's leadership as expressed in metaphors that is contextualized differently across the continents. Taking an interpretive approach, this study seeks to present leadership through the understanding of female leaders involved in the field of education broadly defined, from Rwanda and Bangladesh, who gave accounts of their metaphorical conceptualisation of leadership. Using narrative analysis, these accounts were analyzed to identify and interpret the metaphors emerging from descriptions of leadership experiences. The analysis shows that these leaders used metaphors determined by a dynamic interplay of personal, situational, and cultural factors. Somewhat surprisingly, the metaphors used to present leadership are not always based on a local cultural context, with some explicitly including references to European plants, which could be considered exotic. However, they are not metaphors that fit neatly into the taxonomies recognized in the literature. This study makes an important contribution to the literature on leadership, especially leadership in education. It is one of the few studies focussing on the stories of women from a non-Western background. The pool of case studies presented here is limited, but these metaphors represent thinking tools enabling a scholarly and imaginative understanding of women's leadership in education.

Keywords: metaphors, leadership, women, Rwanda, Bangladesh, cultural context 


\section{INTRODUCTION}

As the literature on women as leaders grows, and discussions of their leadership styles expand, the emphasis continues to be on Western approaches to management and decision-making, often indicating that leadership is a concrete phenomenon, with clear indicators that are innate or that can be developed through deliberate interventions. However, Alvesson and Spicer argue that leadership is not a concrete phenomenon, but rather "something that requires human interpretation and understanding" (2011, 4). This study adopts this approach; it accepts leadership as a concept that exists and is practiced in a given context; to fully grasp how this concept can be understood, a level of interpretation and often of imagination is required.

Understanding something as multi-faceted and intangible as leadership is no easy task, given the complexities of its cultural basis. A positivist approach reducing the concept to measurable variables ensures that the nuances of human interactions, with their inherent cultural understandings are lost. Metaphors have long been acknowledged as a mode of communication which enables some complex, perhaps inexpressible, idea or concept to be expressed in terms of some other phenomenon. In their ground-breaking work, Metaphors We Live By, Lakoff and Johnson (1980) showed how metaphors are so much part of our everyday interactions, that we may not even notice them, but nonetheless, they may influence how we think. Studies of metaphor tend to focus on metaphors deriving from Western cultures, especially in the English language. This study attempts to break that mold, investigating the understanding of leadership as expressed in metaphors by women from two different, non-Western cultures. The power of these metaphors emerges against a background of well-worn metaphors, which may have become shorthand expressions of both what it means to be a leader and also what prevents women in particular from being recognized as leaders.

The reality is that there is greater awareness in the literature and in the workplace of the barriers that women face in reaching not only the highest levels of management but in fulfilling their potential at other levels of organizations. The architectural metaphor of the glass ceiling, where structural elements may impede a woman's progress, came into the vernacular in the 1980s. That its origins are unclear (McGregor, 2016), speaks to the power of the metaphor, which is not only well known but has led to a proliferation of other metaphors to express the impediments to advancement. Some continue with the notion of glass, whereas others focus on the structural element of the ceiling. Whereas the glass ceiling suggests a barrier between levels which is transparent but impermeable, so that those on the floor above can see those below and vice versa without the possibility of passing in either direction, the bamboo ceiling refers to impediments to Asians reaching to the upper levels of the professional world, drawing on a typically Asian building material (Xiao and Handley, 2019). In November 2019 at the African Development Bank Global Gender Summit in Rwanda, Akinwumi Adesina the President of AfDB also referred to impediments, describing the glass ceiling African women leaders experience as a "concrete" ceiling that has to be broken through by a bulldozer (Adesina, 2019). The glass cliff, a term first coined by researchers Ryan and Alexander, 2005 as the result of an empirical study, carries with it the idea of precarious positions, risk and the likelihood of a fall. A metaphor more commonly found in contemporary times in the gender pay equity debate is that of the sticky floor, which is more likely to refer to women in the middle or lower echelons of an organization, and refers to factors which prevent them getting their career off the ground (Laabs, 1993), such as childcare responsibilities or the demands of a partner's employment. A more recent addition to these metaphors of impediment has been the labyrinth. Eagly and Carli (2007) have argued that the glass ceiling is an outdated metaphor and that it is now apparent that there are many barriers and hindrances to career advancement for women. The labyrinth as a metaphor contains within it the notion of success, the possibility of reaching the center and attaining one's goals. It also suggests complexity, a puzzle to be solved and perhaps the need for strategy. This is not the labyrinth of ancient Greece, which acted to contain the Minotaur, and was the site of the triumph of Theseus, but the maze of modern times, and the various connotations attached to it. The use of the labyrinth of videogaming, for example, highlights these factors of success, attaining one's goals and the need for a strategy to reach the center.

These metaphors so frequently used in the context of women employees are not metaphors of leadership, but of barriers and threats to advancement and success, explaining discrimination toward women aspiring to leadership positions (Smith et al., 2012). This is at odds with the way metaphors are used to reflect what seems to be presented as a gender-neutral construct of leadership. According to Oberlechner and Mayer-Schönberger, metaphors present a discursive understanding of leadership. They are not merely wordplay but present an experiential approach to leadership. Taking such an approach, it becomes clear that metaphors are inherently gendered (Oberlechner and Mayer-Schönberger, 2003, 165). At the same time, if one accepts that they are experiential, then this is necessarily the case, because the vast majority of those in leadership positions have been and remain men. It is a much-repeated claim that there are more men CEOs with a particular given name, such as John or Andrew, than there are women CEOs in Australia, or indeed in many other countries (Priestley, 2018). Thus, it will be no surprise that commonly used metaphors related to leadership are male oriented.

\section{LEADERSHIP AND ITS COMMON METAPHORS}

There is a vast literature identifying or classifying metaphors of leadership, much of it reiterating previous analyses. Here, a decision has been made to present two classifications of metaphors, that developed by Oberlechner and MayerSchönberger (2003), and that presented by Alvesson and Spicer (2011). Oberlechner and Mayer-Schönberger's work has had global influence, having been cited by scholars writing in languages other than English, including Chinese, Finnish, German, Korean, Russian, Spanish, and Turkish. The book edited 
by Alvesson and Spicer has been more widely cited, and in a broader range of languages, including Danish, Finnish, French, German, Lithuanian, Norwegian, Portuguese, Russian, Spanish, Swedish, and Turkish. This listing of countries demonstrates the reach of these metaphors, and thus the potential for them to influence the development of local metaphors of leadership. Neither source has been cited in studies related to leadership in Rwanda or Bangladesh, the countries which are the focus of this study.

Long-standing metaphors of leadership relate to war and to sports, according to Oberlechner and Mayer-Schönberger. The language of war and fighting has been frequently used in discussions of strategy, where threats are perceived, and "survival" in the face of "danger" is a key objective; a plan, often a battle plan, needs to be developed, so that winning is a more likely outcome than losing. In this metaphor, others - the enemy may not actually be specified, existing only in the stance taken in the expressions of leadership. However, in metaphors which draw on sport, others are clearly involved. Competitiveness will involve one's own "team" and another team, and both teams will be expected to "play the game." Sports metaphors often include ideas of "fair play," usually including disdain for those who "break the rules"; occasionally, "breaking the rules" is seen as a heroic act, where this act opens up new possibilities for action. Leadership in the context of sports metaphors has a focus on the creation of an environment where cooperation is possible and where a shared objective, "playing the game", is acknowledged. An important function of the leader is the generation of "team spirit," a sense of belonging together which facilitates the development of something amorphous which goes beyond the individual or even the social nature of the collective.

Perhaps in an attempt to soften the somewhat aggressive metaphors deriving from war and fighting and the competitive edge of some sporting metaphors, metaphors related to acting and performing have arisen, although they are not as common. A common metaphor here, according to Oberlechner and MayerSchönberger, is the conductor of the orchestra; this metaphor emphasizes the coordinating role of a leader, creating order and harmony from the various tasks and capacities that make up an organization and its staff. Another metaphor, or cluster of metaphors, which is to some extent less common is the cluster related to spirituality, or occasionally religion. This metaphor presents the leader as being a source and disseminator of hope, with an emphasis on values and beliefs. Charismatic individuals are often at the center of the use of this metaphor. It is also found in times of significant change in organizational culture, especially after misfortune, when the intangibles of hope and inspiration may be necessary to overcome the lack of material substance.

The final metaphor presented by Oberlechner and MayerSchönberger is of the organization as a machine and the leader as the mechanic or engineer responsible for its smooth and safe operation. The machine-organization constantly requires maintenance; one of the leader's responsibilities is to ensure that staff at all levels have access to an appropriately equipped toolbox; that is to say, that they have the knowledge and skills, infrastructure including policies and equipment as well as any other forms of material and non-material support related to the performance of their tasks. The leader controls the operation through its workflows and processes, with systems that keep everything "ticking over."

Alvesson and Spicer's edited collection (2011) introduce six metaphors in a book which seeks to review leadership theory as it is presented in academic publications, media reports, business magazines as well as personal narratives and to clarify contemporary approaches to understanding the concept. Each metaphor presents the notion of leadership through a role recognized in contemporary Western society. The saint as leader, a metaphor which emerges from the conceptual approaches of authentic leadership and servant leadership, is someone with the desirable traits of high moral and ethical standards, who is recognized as the epitome of integrity and who inspires trust in others. The saint-leader seeks to mentor and support others, and to empower them to make decisions which will benefit the collective as much as the individual. This metaphor indicates someone whom others will be keen to follow and to emulate. The gardener is a leader who nurtures others within the context of the organization. The gardener chooses plants suited to the environment and provides the water and nutrients for them to flourish, at the same time modifying the environment, if necessary, by providing shade or sun or pruning to maintain their vigor. In the organizational context, this is a leader who starts at the point of recruitment, and then provides opportunities for professional development and to the employee to meet their own goals and the goals of the organization. This metaphor is often recognized in its negative form, where the gardener-leader must re-invigorate the garden, by removing the "dead wood," "pruning back" expenditure and "weeding out" the dysfunctional or incompetent. A third metaphor which is concerned with positive, supportive relationships that foster individual growth is that of the leader as buddy. The chapter on leaders as buddies is subtitled "leadership by making people feel good." This leader may seek to be "one of the guys," working toward social acceptance as well as holding a hierarchical position; in this way, employees are likely to feel a stronger sense of belonging to the organization, because of these stronger social bonds. The focus on ensuring that people feel good enables them to deal better with the stresses and strains of the modern workplace and, consequently, improve their performance. The buddy-leader frequently uses the pronoun "we," in talking about the work group.

The leader as commander suggests a military environment, with a strong authoritarian approach. This leader "leads from the front," giving clear direction and expecting to be followed. He or she is likely to be driven to succeed and unwilling to tolerate failure in others in themselves, often leading to a close surveillance of the tasks, actions and performance of subordinates. The commander-leader will ensure that people are well-trained and aware of the part they are expected to play in the overall plan; they are likely to be valued for their ability to develop strategic plans and to make effective decisions quickly. The fifth metaphor is of the leader as cyborg. Somewhat akin to the leader as commander, the leader as cyborg is driven to succeed, usually putting the organization and its objectives before family and friends, and promoting the view that failure is not an option. This metaphor is an appropriate one for an organization 
concerned with technology and technological development as it casts the leader as not fully human. This is a leader who does not show emotion or seek social bonds, but rather prefers to work with like-minded employees who are already or who can train to become high achievers. Being more than human, the leader as cyborg presents an image of being superior, expecting to win in any competition, and is usually considered to be extra-ordinary. This is a characteristic which enables the cyborg-leader to break the rules in order to achieve a goal. This form of charismatic leadership is not dependent on masculine stereotyping. To some extent, organizations help in the creation of this kind of metaphor by recruiting senior managers with unrelenting energy to make rapid radical change, with an eye to achievement of perfection. The final metaphor is of the leader as bully, although employees in many organizations might claim that this is not a metaphor for leadership, but a reality. The bully is often seen as disruptive in social settings, and such behavior is not to be tolerated. However, this leader exercises control and can maintain a significant level of stability in an organization, marginalizing those who oppose its values or direction. The leader-bully intimidates opponents and creates outsiders, often through ridicule and shame.

There are relatively few studies focusing on metaphors relating to women as leaders, although there are studies in the field of education of the metaphors used to represent the leadership of school principals, where some of the principals would have been women. One study of women principals conducted in the United States (Colflesh, 2000) identified four metaphors from the ways they identified themselves and their work. These included: the cultural connecting leader, the trusted family focused leader, the servant leader and the leader of the school family of learners. Perhaps more interesting though than the categorization are the ways that participants in this study described themselves. The metaphors of the hub of a wheel and the nucleus of an atom, surrounded by protons and neutrons, were strikingly similar in their representation of a center and periphery. The participant drawing the nucleus with protons and neutrons "[did not] want to be here in the center by myself." The notion of leadership being involved with the center of activities was reinforced by another metaphor, this time of a web, with the particular individual in the center aware that there are other webs over which the individual has no control. Two participants used musical metaphors, one of being a performer in a symphony orchestra, aware of the other musicians and their roles as well as the challenges of the particular score to be performed; the other took a position as conductor of a symphony orchestra, rehearsing for a major concert, experiencing highs and lows, being able to sight-read the score and willing to dedicate time to practice (although the role of conductor is not specifically mentioned). An interesting aspect of this study is that these women mixed the metaphors as they sought to express different aspects of their role.

A similar approach, analyzing the ways that women spoke about themselves as leaders, was used in a study conducted in South Africa. Like the study conducted by Colflesh (2000), this study of school principals by Phendla (2004) used the naturalistic language of the women themselves to identify metaphors. She notes that metaphors are "so ordinary" $(2004,166)$ that they can reveal the powerful, colorful thinking of people in their everyday understandings of leadership, but she also assumed that the women, through their roles, were engaged in service to others. Three women took part in this study, and each presented more than one metaphorical expression of leadership. These included being a magnet, which attracts others; being a star, shining in the darkness; being the driver of a car, where others are the engine that actually makes the car work; being a mountain climber; being like the sunshine, which "brings a sense of a happy environment"; being like water in the desert; supporting fragile things. These metaphors are not part of the ritual of referring to leadership in a hackneyed, learned way, but rather they give a strong sense of individual, personal engagement with what it means to be a leader.

\section{METHODOLOGY}

In the context of this literature, which presents an overwhelmingly gendered approach to the metaphorical expression of leadership, this study sought to continue with the trend which takes the perspectives of a small number of individual women and explores the multiplicity of metaphors they use to describe their own perspectives on leadership. Leaders are influential not only through what they achieve in the physical world but also through the communication of their ontological perspectives. An analysis of the studies of metaphors used by leaders indicates two common approaches. The first is the analysis of language used in publications, whether speeches or discussions of leadership and its functions. The second, less common, is the interpretation of the metaphors of individual leaders. The first approach tends to reinforce existing metaphors, using and re-using similar ideas. The second conceptualizes respondents as key informants, acknowledging their particular expertise. The use of key informants, a recognized data collection technique in qualitative research methods (Bernard, 2018), gives the researcher access to specialist knowledge embedded within its cultural context. Used in the context of this study, it is an approach that draws on the creativity of the individual, seeking to identify views of leadership which are not constrained by the cliched language of management-speak.

Leaders in business and industry are commonly used as key informants, as are those acknowledged as being outstanding in their cultural context (O'Leary, 2014, p. 192). Researchers acknowledged as leaders in a field are generally deemed to be in a strong position to identify other leaders in that field. For this study, the position of one of the researchers and her extensive experience of working internationally facilitated the identification women leaders. The idea of a project to uncover the ways women from the Global South conceptualize leadership was suggested and a number of women were invited by email to participate. These women included school principals, government officials, politicians and members of civil society. They were asked to think of a metaphor that represented their perception of themselves as leaders and to explain how the metaphor worked and why they had used it. Although the women were promised anonymity in any resulting scholarly work, they acknowledged their position in their own society and were even 
eager to be associated with the metaphor they presented; here they are represented by names they chose. The need to write in English was a deterrent and lack of confidence in this prevented some of the women from taking part. Even some of the women who did take part found writing their metaphors and stories very difficult, so that their contributions were relatively brief. Their accounts were then analyzed to draw out the metaphors used and situate them in a broader context. The process of analysis used Barthian narrative analysis, drawing particularly on his cultural code, which uncovers the background knowledge on which a text relies (Barthes, 1972). This analysis required consideration of the individual and the ways they may be used to conveying their thoughts, knowledge and understanding. It demonstrated that these metaphors are determined by a dynamic interplay of personal, situational, and cultural factors.

Seven women, four Rwandans and three Bangladeshi, sent usable contributions. The ages of the women range from 35 to 70 , with five being in their 40-50s. All are gender experts and human rights advocates. Three have Ph.D.s and four have master's degrees from universities in Australia, United Kingdom, Canada, and Rwanda. Six of the women have visited and studied outside of their country and five have worked and lived outside. Three women are senior academics, two of them in the United States. They are all involved in international development projects, using their professional and academic expertise, as well as in community associations. Two are senior officers with international development agencies based in their country, and both are also involved in gender issues at the national level in their countries. One acts as a national consultant in gender and poverty policy and practice to several government ministries and international development partners and one is a very senior official in a government department. They each recognize and are recognized for other aspects of their identities, including singer, poet, writer, artist, mother, grandmother, mentor, and advocate.

\section{FINDINGS}

\section{Women and Their Metaphors of Leadership}

The women took varying approaches to presenting their metaphors. Some were extended and elaborated whereas others were very brief. The more elaborated presentations give wider scope for narrative analysis, but even the brief presentations are imbued with significant cultural connotations.

Rosette began her presentation of the metaphor with a muchquoted aphorism from an American newspaper columnist, Doug Larson: "A weed is a plant that has mastered every survival skill except for learning how to grow in rows." She chose as her metaphor "a dandelion - a weed to most and a flower to some. No matter what side you fall on the weed/flower dichotomy, we all reckon with the persistence of the dandelion. The dandelion is known for its persistence and adaptability. In the United States and Canada, season after season, lawn after lawn, the dandelion shows up again and again, setting down deep roots and reproducing itself in neighboring lawns by turning its pretty little flower into puffballs, whose seeds are blown by the wind (or children) into the next place, where new dandelions set down roots and bloom and the cycle continues. Dandelions are also known to repel destructive worms while attracting honey bees and to support plants with weaker roots. This may be why some "naturalist" gardeners do not seem to mind them so much." The persistence of the dandelion is echoed in her descriptions of the leadership challenges she has faced.

Justine wrote that she was familiar with the metaphors for leadership used in her Christian faith, but that she did not find those appropriate. Eventually she "settled on a camel's life: an animal which mirrors my resilience, patience and life experience. Camels are survivors against all odds: through bad weather, famine, and drought, they humbly serve to the last minute. Camels have fat in their humps that help them endure hunger longer than other animals." Camels also kick, and these "kicks turn out to become my strength to overcome the next challenge." She goes on to report that, "Like camels - which drink a lot of water in one go and can survive on it for quite some time - when I am given an opportunity for learning (or imparting knowledge), I drink it in and as fast as I can!" Camels have stamina and are well regarded for their persistence and grace.

Colette's description of the metaphor she would use for herself as a leader was short and to the point, when she wrote: "I like the picture of a cat looking in a mirror, with a tiger reflecting back. What you think of yourself is more important than what you think others think of you." Then, quoting Eleanor Roosevelt, she asserted: "No one can make you feel inferior without your permission."

Dimitrie, like Justine, found it difficult to choose a single metaphor, but eventually decided: "I think I am more like a "Hedera Helix," as a flowering plant. It is also called English Ivy and you can find it in almost all areas of the world. English ivy is evergreen, very tolerant of shade and will grow in full sun. In the adult or reproductive phase, English ivy produces a woody erect stem either from the ground or growing off existing climbing vines. Its tolerance to changes makes it very resilient. It can take multiple forms, can be used for different purposes including ornamental and medicine, it can be planted indoor or outdoor, and lives long because it resists weather and all sorts of turbulences. I found myself adjusting and adapting to many situations, bad or good, but I can't give up on my dreams and goals."

Jebunnessa wished that she could be a boa constrictor. In writing about challenges she faced, she said "During that time I felt that I have to win. I thought that I am a boa, but I don't know how to swim. Slowly I learnt to float in water and tried. I won."

Baby presents herself as a tree, modeled on her grandmother's love of trees. "My roots are my confidence that I have developed by learning and experiencing and sharing and being bold in my work. My branches are the shades of trust that people can ... rely on. I never give up, like big trees, and that is my resilience."

Tajkera is the only one of the seven who did not follow the request to present a single metaphor. She began by writing that those around her say that she is like a rhino, because of her thick skin which has enabled her "to absorb every discouraging words I had to face in the past ... and move forward ... to develop our women in need." She concluded that "without being 
a Rhino I would not be able to work in the women development sector in Bangladesh." Her second metaphor is the turtle, which she presents as an analogy for her patience, using an example to show the length of time it took to achieve a change. Her third metaphor is somewhat more difficult to grasp for these researchers. She writes: "I think I have a brain like flamingos in terms of leadership" and goes on to write: "I trained my team my flock - how to walk even in between the salty lake of life and overcome all the obstacles."

\section{DISCUSSION}

\section{Interpreting These Metaphors}

Metaphors provide a stimulating way to understand leadership and what women really mean when discussing leadership. These women presented interesting images of themselves as leaders. They all acknowledged that metaphorical thinking was difficult for them and technically, they have presented analogies, rather than metaphors, likening themselves to another phenomenon, and through this process identifying the characteristics which they believe have enabled them to be successful.

The question of why the process of identifying a metaphor to present their view of leadership was difficult was not asked. In retrospect, three possible answers come to mind. The first is that these women are used to dealing in a world of strategic reality, so that metaphorical thinking does not come easily to them, and they have not previously considered themselves from this perspective. Tajkera and Baby, two of the women from Bangladesh, chose analogies that have arisen from their social interactions with others, Tajkera referring to conversations with her husband and Baby to her grandmother; Rosette, from Rwanda, identified herself as having a hobby as a gardener, and using that as the basis for her choice. Justine, however, deliberately set aside metaphors used in her Christian faith. Thus, to some extent, the metaphors these women presented are not "ordinary" or "invisible" as Colflesh (2000) or Phendla (2004) claimed the metaphors expressed by the subjects in their study to be. Instead, they have been selected for the purpose of responding to a question from a researcher. This does not negate their value but adds to the complexity of interpreting their meanings.

A second answer to why metaphorical thinking does not come easily is that their backgrounds have largely been in the sciences and in policy development, where observations of the natural world have influenced their ways of thinking, and in academe, which values particular ways of presenting ideas. Dimitrie's description of English ivy, along with its Latin name, could be an entry from an encyclopedia; it describes the habitat of the plant and its way of growing; Rosette's description of the dandelion similarly could have come from a gardener's handbook, setting out the characteristics which make it a plant that is at the same time a weed and a valued part of the ecosystem. Justine's description of the camel could have come from a textbook or encyclopedia intended for children. Each of these analogies is presented in a structured, analytical way, so that its appropriateness could be justified. Rosette and Colette each use an additional way to situate their metaphorical thinking, the reference to the thoughts and beliefs of others, through quotation. Rosette uses a quote from a popular commentator, Doug Larson, as a kind of epigraph in the presentation of her metaphor; it appears as a heading to her work, suggesting the theme to her metaphor, in this case, the significant strengths of the weed. Colette's presentation of her metaphor is extremely brief, but her inclusion of a quote from Eleanor Roosevelt positions it in a context of a strong woman, making opportunities to argue for social justice and to achieve significant change.

A third answer to why metaphorical thinking did not come easily to these women is that they were aware of the need to create a bridge between themselves and the researchers, who did not share their cultural background. In other words, the very setting of the request precluded the assumption of the "ordinary" and the "invisible" which underpins much of the analysis of the use of metaphorical language. The two gardening metaphors are situated in a setting from the global North, with the references to English ivy and the dandelion; although the mapping of the characteristics of these plants is clearly to the Rwandan experiences, the metaphors are not drawn from the Rwandan experience of these women. Nonetheless, they are very easy to interpret, bringing together elements of both cultures. Similarly, Baby's use of the tree is something which is clearly of her culture, coming from her grandmother, but at the same time, it is a metaphor which is easily understood, regardless of cultural heritage. Colette's use of the cat in the mirror suggests a first world setting where cats are pets, living inside a human dwelling, with mirrors that feed back to the observer a sense of their own identity, at the same time incorporating the idea that external perceptions may be at odds with the individual's sense of identity. Jebunnessa's boa constrictor is both something familiar and at the same time something beyond the experiences of the researchers. It is known as a very strong creature capable of overwhelming others, slow on the land but in the water a powerful swimmer; but also a snake which is reclusive, preferring to keep a low profile, using its tremendous strength only in a purposeful way.

Thus, we come to Tajkera's metaphors. The protection offered by the tough skin is well recognized in the English-speaking world by those with no personal experience with the rhinoceros. Interpreting the metaphor of the turtle and its relationship to patience may be more difficult. It is not clear whether, in naming the turtle, Tajkera is referring to the tortoise, the landbased creature of Aesop's fable or the water-dwelling turtle more commonly found in North America. Regardless, this creature is well represented in folk stories, whether from Africa or from Native Americans or from South Asia, where it is recognized for its tenacity and patience, as well as for its cunning (Garfield, 1986; Werner, 1993). However, the relationship between the flamingo, Tajkera's brains and leadership may not be readily apparent. Flamingos are exotic birds to Australians, found in zoos, where they are the epitome of grace with their long legs and beauty with their pink feathers, and in storybooks such as Alice in Wonderland where they have a surreal existence as the mallets for a game of croquet. To try to make sense of this metaphor, the researchers sought to know more about the flamingo from a Bangladeshi perspective, and the information found proved enlightening. Flamingos were reported to have been endemic to 
Bangladesh, although none had been reported for a number of years, until 2017, when news was made after a group of hunters shot and killed a bird with which they were unfamiliar, later identified as a greater flamingo (Ahmed and Mahmud, 2018). To interpret the metaphor, we considered it useful to consider the next utterance, training the flock to walk in the salty lake of life. The wetlands where flamingos live are likely to be salty and relative shallow sheltered waters; a feature of them is that the bottoms are usually muddy and uneven, requiring the flamingos to use their broad webbed feet to maintain balance, but also skill in navigating areas prone to flooding and therefore potentially with submerged obstacles. Thus, the flamingo in Bangladesh is a noteworthy bird, rarely seen; it lives in flocks and is potentially well adapted for its environment, although the flock relies on the skills and expertise of some of its members to survive and thrive in its environment. Whether this is what Tajkera had in mind when she wrote of "brains like flamingos" is not known, but from our Australian perspective, this seems a reasonable way to create meaning about leadership from this figure of speech, using Barthian narrative analysis (Barthes, 1972).

\section{Identifying the Ethics of Leadership}

Leadership metaphors carry messages about the ethics of leadership, suggesting what is good, what should be done, and how. The metaphors presented by these seven women carry very strong messages about their perceptions of what it means to be a leader and to act as a leader, messages which are largely invisible until the metaphors used have been interpreted. Common threads run through these presentations, with some displaying ideas that are common to discussions of leadership and others being novel. Among those that are common to discussions in the literature are persistence, resilience and belief in oneself, as well as an emphasis on support for others, whether through the shade of Baby's tree, the roots of Rosette's dandelion or the guidance of Tajkera's flamingo. To the extent that these women recognized themselves as transformational leaders, persistence may be sometimes presented as patience, the quiet and firm waiting for an opportunity, and tolerance may need to encompass the acceptance of opposing points of view, or to acknowledge that different approaches may lead to a similar end.

Confidence also may have two sides to it. Colette's cat that sees a tiger in the mirror, along with the quote from Eleanor Roosevelt emphasizes the importance of having confidence in oneself. That confidence in oneself is also evident in the roots of Baby's tree. It is also important for others to have confidence in a leader. Rosette describes how the dandelion makes itself attractive to insects and to gardeners, so that others are persuaded of the importance of its contribution. Justine's camel engenders confidence in others because of its reputation as a survivor which is always there to help and support people.

The metaphors also show that leaders are able to go beyond the ordinary. The dandelion spreads easily from field to field, the ivy has many uses, the tree becomes a landmark in the landscape, the cat becomes a tiger and the camel's great thirst enables the uptake of new information very quickly, with the processing of those ideas going on over a considerable period of time, even well after the ideas generated by others have dried up.
A key factor in identifying the ethics of leadership is that sometimes it is important to recognize that actions must provoke opposition, if changes are to be made. Justine writes of how the camel can be a humble servant, but at the same time, it can kick out and be destructive; these kicks are a way of signaling points that are valuable and must be fought for. Jebunnessa's boa can easily overpower other creatures, including ones many times its size, but it prefers not to be aggressive. Rosette identifies the dandelion as being both a problematic plant and a positive contribution to a garden; in particular, the ease with which the dandelion spreads is seem as problematic. Dimitrie's ivy is presented by her only as being useful for a range of purposes, although it would seem that she is also aware that its resilience and ability to grow in a variety of conditions can lead to it becoming an annoyance. Tajkera's need for the rhino's thick skin to manage the forces of opposition is another example.

Tajkera's flamingo is an instructive metaphor on the ethics of leadership by women. Sightings of this bird are uncommon, and yet the bird can be expected to live in these areas, according to the expertise of ornithologists; once established, it works to support the collectivity of the flock, potentially able to achieve what other birds cannot, in the relatively hostile environment of the mud beneath the salty water. It does not seem too much of a stretch to consider that female leaders may also be uncommon, although their existence is acknowledged; and these female leaders support others to survive and thrive in what can be perceived as difficult circumstances.

Being aware of these messages is an important basis for ethical leadership. The principles and values embedded in the metaphors are not explicit but are evident to anyone willing to make some minimal effort in interpreting them. Seeing these principles and values only as a checklist of aspirational features weakens them and undercuts the ethical foundation from which they arise. Ethical practices arise in a system of human interactions and the metaphors establish the frames of reference within which the principles and values should be understood. It is this understanding which enable Rosette, Justine and Dimitrie to be clear that the metaphor they have chosen portrays a leader having the capacity for harm or damage at the same time as having the capacity for positive change. However, this approach is far removed from the oppositional metaphors found in the literature, where the focus is on war and fighting, with notions of battles and winners and losers (cf Oberlechner and Mayer-Schönberger, 2003). Instead, the metaphors presented by these women indicate that struggles will be inevitable and that sometimes strong action will be called for so that the end goal of transformation is achieved.

\section{CONCLUSION}

This study set out to present metaphors that women leaders in non-Western contexts use to communicate their concepts of leadership and it has presented an analysis of metaphors presented by seven women from Rwanda and Bangladesh. The study has shown that the metaphors used by the women in this study are not influenced by the metaphors commonly 
found in the organizationally based literature on metaphors and leadership. The metaphors they have presented provide a stimulating way to understand leadership and what women really mean when discussing it. The analysis of these leadership stories shows that the metaphors they use are determined by a dynamic interplay of personal, situational, and cultural factors. It has also shown that there has to be a shared cultural understanding for a metaphor to provide insight into the concept of leadership.

This need for shared cultural understanding in easily understanding what someone means when they use a metaphor in turn raises questions about the choices open to participants in cross-cultural research of the kind envisaged here. We had hoped to bring to light metaphors used by women acknowledged as leaders in their communities which are far removed geographically from Australia and the global north from which our scholarly traditions derive, and in so doing to give them a voice in this globalized scholarship. Yet the very process we used meant that they were likely to think about how to communicate their thoughts and practices across this cultural distance and thus to choose metaphors that we in the global north could relate to.

The study has supported Alvesson and Spicer's contention that leadership exists both as a concept and as a practice, and that imagination is important both for its expression and its understanding. The women clearly used a process of imaginative thinking to come up with the metaphors. These were not examples of the ordinary and invisible use of language found in other studies. Further, understanding some of these metaphors required imagination on the part of the researchers. In other words, these metaphors were deliberately developed to convey both the abstract and the practical, rather than being a part of the everyday discourse of leadership.

Leadership is portrayed here, by at least some of the women, both as a series of attributes and as a range of practices to be understood within their context. This context may necessarily involve generating opposition because without that opposition there can be no significant change; however, the opposition is not cast in terms of winners and losers. The significance of context also means that the attributes cannot be separated from the women and the context in which they found themselves and turned into a checklist of desirable characteristics.

Finally, this study cannot make claims about whether the use of the metaphors presented here is gendered. It can only state that these metaphors were presented by women in response to a request from a researcher. It may be that the language of

\section{REFERENCES}

Adesina, A. (2019). Inaugural Session. Kigali, Rwanda: Global Gender Summit.

Ahmed, A., and Mahmud, H. (2018). First record of greater flamingo phoenicopterus roseus from south east coastal, Bangladesh. Bangladesh J. Zool. 45, 185-188. doi: 10.3329/bjz.v45i2.35713

Alvesson, M., and Spicer, A. A. (2011). Metaphors We Lead By; Understanding Leadership in the Real World. Abingdon: Routledge. doi: 10.4324/9780203840122

Barthes, R. (1972). Mythologies. New York, NY: Hill and Wang.

Bernard, H. R. (2018). Research Methods in Anthropology: Qualitative and Quantitative Approaches, 6th Edn, Lanham, MD: Rowman and Littlefield. management and leadership is already so gendered that it will be difficult to maintain everyday discussion of the concept and practice without using language with those invisible metaphors.

This exploratory study, with its strengths and limitations, is a starting point for research on a topic of importance in a globalizing world. There is certainly scope for further research by women on women's use of metaphors in expressing notions of leadership in a range of different contexts and cultural settings.

\section{DATA AVAILABILITY STATEMENT}

The datasets generated for this study will not be made publicly available. We would need agreement from each individual participant to release their "stories".

\section{ETHICS STATEMENT}

Ethical review and approval was not required for the study on human participants in accordance with the local legislation and institutional requirements. The patients/participants provided their written informed consent to participate in this study. Written informed consent was obtained from the individual(s) for the publication of any potentially identifiable images or data included in this article.

\section{AUTHOR CONTRIBUTIONS}

SR and HY contributed conception and design of the study, and analyzed the statements. SR obtained the written statements of leadership experiences and metaphor from respondents. HY wrote the first draft of the manuscript. Both authors contributed to manuscript revision, read and approved the submitted version.

\section{ACKNOWLEDGMENTS}

Without the interest from a number of women leaders in Rwanda and Bangladesh, this work would not have been possible.We express our thanks to the seven women who provided the written statements on which this study is based: Baby Rani Karmakar, Colette Nyinawumuntu, Dimitrie Sissi Mukanyiligira, Jebunnessa, Justine Uvuza, Rosette Adera, and Tajkera Khair. 
McGregor, J. (2016). How the 'Glass Ceiling' Became Such a Powerful and Problematic - Metaphor. The Washington Post. Available online at: https://www.washingtonpost.com/news/on-leadership/wp/2016/06/09/howthe-glass-ceiling-became-such-a-powerful-and-problematic-metaphor/ (accessed June 10, 2016).

Oberlechner, T., and Mayer-Schönberger, V. (2003). Through their own words: towards a new understanding of leadership through Metaphors. Paper Presented at the Center for Public Leadership Working Papers Series 159, Cambridge, MA. doi: $10.2139 /$ ssrn. 357542

O’Leary, Z. (2014). The Essential Guide to Doing your Research Project, 2nd Edn, Los Angeles, CA: Sage.

Phendla, T. (2004). Metaphors of leadership, metaphors of hope: life stories of black women leaders in South Africa. Afr. Educ. Rev. 1, 161-174. doi: 10.1080/ 18146620408566277

Priestley, A. (2018). More 'Andrews' than Female CEOs Leading Australia's Top Companies. Women's Agenda. Available online at: https://womensagenda.com. $\mathrm{au} /$ uncategorised/still- more-andrews-than-female-ceos-leading-australianorganisations (accessed March 6, 2018).

Ryan, M., and Alexander, H. (2005). The glass cliff: evidence that women are over-represented in precarious leadership positions. Br. J. Manag. 16, 81-90. doi: $10.1111 / j .1467-8551.2005 .00433 . x$
Smith, P., Caputi, P., and Nadia, C. (2012). A maze of metaphors around glass ceilings. Gender Manag. 27, 436-448. doi: 10.1108/1754241121127 3432

Werner, A. (1993). Myths and Legends of the Bantu. London: Harrap.

Xiao, B., and Handley, E. (2019). How Asian-Australians are Struggling to Break Through the 'Bamboo Ceiling'. ABC News. Available online at: https://www.abc.net.au/news/2019-11-02/asian-australiansstruggling-to-break-bamboo-ceiling/11665288 (accessed November 2, 2019).

Conflict of Interest: The authors declare that the research was conducted in the absence of any commercial or financial relationships that could be construed as a potential conflict of interest.

Copyright (๑) 2020 Randell and Yerbury. This is an open-access article distributed under the terms of the Creative Commons Attribution License (CC BY). The use, distribution or reproduction in other forums is permitted, provided the original author(s) and the copyright owner(s) are credited and that the original publication in this journal is cited, in accordance with accepted academic practice. No use, distribution or reproduction is permitted which does not comply with these terms. 